Research Article

\title{
Comprehensive Evaluation Model of Environmental Quality in Ecological Reserve
}

\author{
Songjia Zhang $\mathbb{D}^{\mathrm{D}}$, Weiyang Yu, and Teng Chen \\ School of Economics and Management, Yanshan University, 438 Hebei Street, Haigang District, Qinhuangdao, Hebei, China \\ Correspondence should be addressed to Songjia Zhang; alan_zsj@qq.com
}

Received 14 June 2021; Revised 8 August 2021; Accepted 15 October 2021; Published 19 November 2021

Academic Editor: Daqing Gong

Copyright ( $\odot 2021$ Songjia Zhang et al. This is an open access article distributed under the Creative Commons Attribution License, which permits unrestricted use, distribution, and reproduction in any medium, provided the original work is properly cited.

\begin{abstract}
The environmental quality of the ecological protection zone directly affects the water quality and air quality of the area, thereby affecting the quality of people's life. This paper constructs the evaluation index system of the environmental quality of the ecological protection area and determines the classification standards of each index, proposes the extension evaluation method of the environmental quality of the ecological protection area, and uses the entropy weight method to determine the weight of each level of index. Its purpose is to understand the development trend of environmental quality in all aspects of the ecological reserve through the dynamic evaluation of the environmental quality of the ecological reserve, so as to take corresponding countermeasures to promote the healthy development of the area. The constructed model was used to dynamically evaluate the environmental quality of the ecological reserve in Zhangjiakou City from 2008 to 2019. The research results show that the environmental quality gaps in different aspects of the ecological reserve of Zhangjiakou City are relatively large, and the overall regional ecological environment characteristic value is decreasing year by year, reflecting that the environmental quality of the ecological reserve of the region is getting better year by year.
\end{abstract}

\section{Introduction}

Ecological reserve refers to the area that plays an important role in water and soil conservation, flood regulation, windproof and sand-fixing, and maintenance of biodiversity. It also selectively delimits a certain area for key protection and restricts development and construction. Domestic and foreign scholars use different methods to study the quality of ecological environment from different angles. Dong and $\mathrm{Mu}$ [1] constructed an evaluation index system from three aspects of economy, society, and environment to evaluate the environmental quality of Beijing's ecological conservation development zone. Xu et al. [2] selected a multilevel weight analysis decision method (the AHP method) to quantitatively evaluate the water conservation area in the southern mountainous area of Jinan, China. Lin [3] constructed an evaluation index system from five aspects, ecological function, ecological structure, and ecological stress, and evaluated the ecological environment of the ecological function area of water conservation in Fujian Province,
China. Gan and Zhang [4] evaluated the ecological function areas of the Yangtze River Economic Zone in China by constructing three indexes: ecological function, ecological structure, and ecological stress. Zhang and $\mathrm{Du}$ [5] used the extension comprehensive analysis method to evaluate the ecological function areas of glaciers and water conservation in Qilian Mountains in China. Chai and Lha [6] determined the key indicators of ecological environment quality through a dynamic collaborative word network and constructed an ecological environment quality evaluation model. Jia et al. [7] applied the map overlay method to comprehensively analyze the ecological reserve of the Daqing River Basin in Beijing. Chai et al. [8] used the "pressure-state-response" model to evaluate the quality of the ecological environment in Beijing. Gao and Chen [9] gave suggestions for the future research directions of ecological environment quality evaluation from four aspects: evaluation object, evaluation content, evaluation system, and evaluation method.

This paper will build the environmental quality evaluation index system of ecological reserve according to the 
characteristics of ecological reserve, determine the classification standards of each index according to relevant standards and scholars' research results, build the extension evaluation method and weight determination method, and apply the constructed model to comprehensively and dynamically evaluate the ecological environmental quality of ecological reserve in Zhangjiakou China.

\section{Construction of Evaluation Index System and Model}

According to the "Technical Specification for Evaluation of Ecological Environment Conditions” and scholars' research results, the ecological environment quality evaluation system of ecological reserves includes two categories: ecological conditions and environmental conditions. The specific composition of the index system is shown in Table 1.

2.1. Indicators of Ecological Conditions. The indicators of ecological conditions include two first-level indicators of ecological function and ecological structure. The first-level indicators of ecological function include two second-level indicators of per capita water source and population density; the first-level indicators of ecological structure include two second-level indicators of forest coverage and green coverage of built-up areas.

2.2. Indicators of Environmental Conditions. The indicators of environmental conditions include three first-level indicators of pollution load, environmental control, and environmental quality. The first-level indicators of pollution load include four second-level indicators: solid waste emission intensity, wastewater emission intensity, industrial sulfur dioxide emission intensity, and industrial smoke and dust emission intensity. The first-level indicators of environmental control include three second-level indicators: the comprehensive utilization rate of industrial solid waste, the rate of harmless treatment of garbage, and the rate of centralized treatment of urban sewage. The first-level indicators of environmental quality include two second-level indicators, the surface water quality index and the air quality index. The calculation methods for these two second-level indicators can be found in the relevant literature of Yu et al. [10].

\section{Classification of Evaluation Index Categories}

3.1. Basis for the Classification of Evaluation Index Categories. When evaluating the environmental quality of an ecological reserve, it is necessary to scientifically classify each evaluation index. The classification principles are mainly based on the following principles:

(1) Based on the assessment standards of relevant national documents, combined with the actual situation of the ecological reserve, with reference to the national ecological evaluation index system, the main reference basis is "National Forest City
Evaluation Standard," "National Water Ecological Civilized City Evaluation Standard (Trial)," and "National Ecological Garden City Standard"

(2) Based on the classification standard of scholars' research results, the classification standard of environmental pollutant discharge is based on the research results of Liu et al. [11] and the classification standard of solid waste discharge intensity and wastewater discharge intensity refers to the research results of Wang [12]

3.2. Classification of Evaluation Index Categories. To comprehensively evaluate the environmental quality of the ecological reserve, according to the research needs, the indicator categories are divided into five categories, namely, very good, good, general, poor, and very poor, and the corresponding categories are Class I, II, III, IV, and V. See Table 1, for specific classification criteria.

\section{Construction of the Evaluation Model}

4.1. Selection of the Evaluation Model. For the evaluation of ecological environment quality in ecological reserves, the choice of evaluation methods is particularly important for the accuracy of the evaluation results. The extension evaluation method considers the uncertainty of the ecological environment in the ecological reserve and pays attention to the ambiguity of the index boundary, which can reflect the evaluation level and reflect the degree of the evaluation result to the evaluation level. In this paper, the extension evaluation method is used to evaluate the ecological environment quality of ecological reserves. At the same time, the weight determination method in the traditional extension evaluation method is improved. The entropy weight method is used to determine the weight of the evaluation index, which can effectively avoid the influence of human factors on the weight.

4.2. Construction of the Evaluation Model. As can be seen from the evaluation index system in Table 1, this index system is a multilevel index system in which the first-level index is evaluated first, and then, the overall evaluation object is evaluated.

4.2.1. Extension Evaluation Method for First-Level Indicators. The extension evaluation method is an evaluation method that establishes an evaluation model that includes multiple index parameters and performs cluster analysis by constructing an extension correlation matrix to reflect the comprehensive level of the object being evaluated. The following describes the evaluation steps of this method for the first-level indicators.

(1) Determine the same characteristic matter element $R_{0}$ in the classic field. In the extension evaluation method, the evaluation objects and first-level indicators are divided into $m$ categories. Assuming that the first-level index has $n$ second-level indicators, 
TABLE 1: Environmental quality evaluation index system and index classification standards of ecological reserves.

\begin{tabular}{|c|c|c|c|c|c|c|c|}
\hline Index category & $\begin{array}{l}\text { First-level } \\
\text { indicators }\end{array}$ & Second-level indicators & Class I & Class II & Class III & Class IV & Class V \\
\hline \multirow{4}{*}{$\begin{array}{l}\text { Ecological } \\
\text { conditions }\end{array}$} & \multirow{2}{*}{$\begin{array}{l}\text { Ecological } \\
\text { function }\end{array}$} & $\begin{array}{l}\text { Per capita water resources }\left(\mathrm{m}^{3} /\right. \\
\text { person) }\end{array}$ & $2000 \sim 2500$ & $1500 \sim 2000$ & $1000 \sim 1500$ & $500 \sim 1000$ & $0 \sim 500$ \\
\hline & & Population density (person $/ \mathrm{km}^{2}$ ) & $0 \sim 25$ & $25 \sim 50$ & $50 \sim 75$ & $75 \sim 100$ & $100 \sim 125$ \\
\hline & \multirow[b]{2}{*}{$\begin{array}{l}\text { Ecological } \\
\text { structure }\end{array}$} & Forest cover rate $(\%)$ & $40 \sim 50$ & $30 \sim 40$ & $20 \sim 30$ & $10 \sim 20$ & $0 \sim 10$ \\
\hline & & $\begin{array}{c}\text { Green coverage rate in built-up } \\
\text { area }(\%)\end{array}$ & $40 \sim 50$ & $30 \sim 40$ & $20 \sim 30$ & $10 \sim 20$ & $0 \sim 10$ \\
\hline \multirow{9}{*}{$\begin{array}{l}\text { Environmental } \\
\text { conditions }\end{array}$} & \multirow{5}{*}{ Pollution load } & $\begin{array}{l}\text { Solid waste emission intensity (ten } \\
\text { thousand tons } / 100 \text { million yuan) }\end{array}$ & $0 \sim 0.8$ & $0.8 \sim 1.6$ & $1.6 \sim 2.4$ & $2.4 \sim 3.2$ & $3.2 \sim 4.0$ \\
\hline & & $\begin{array}{l}\text { Wastewater discharge intensity } \\
\text { (10,000 tons/100 million yuan) }\end{array}$ & $0 \sim 2.0$ & $2.0 \sim 4.0$ & $4.0 \sim 6.0$ & $6.0 \sim 8.0$ & $8.0 \sim 10.0$ \\
\hline & & $\begin{array}{l}\text { Industrial sulfur dioxide emission } \\
\text { intensity (ton/100 million yuan) }\end{array}$ & $0 \sim 5.0$ & $5.0 \sim 10.0$ & $10 \sim 15.0$ & $15.0 \sim 20.0$ & $20.0 \sim 25.0$ \\
\hline & & $\begin{array}{l}\text { Industrial smoke and dust emission } \\
\text { intensity (tons } / 100 \text { million yuan) }\end{array}$ & $0 \sim 8$ & $8 \sim 16$ & $16 \sim 24$ & $24 \sim 32$ & $32 \sim 40$ \\
\hline & & $\begin{array}{l}\text { Comprehensive utilization rate of } \\
\text { industrial solid waste (\%) }\end{array}$ & $85 \sim 100$ & $70 \sim 85$ & $55 \sim 70$ & $40 \sim 55$ & $25 \sim 40$ \\
\hline & \multirow[t]{2}{*}{$\begin{array}{l}\text { Environmental } \\
\text { control }\end{array}$} & $\begin{array}{c}\text { Harmless treatment rate of garbage } \\
(\%)\end{array}$ & $90 \sim 100$ & $80 \sim 90$ & $70 \sim 80$ & $60 \sim 70$ & $50 \sim 60$ \\
\hline & & $\begin{array}{c}\text { Centralized treatment rate of urban } \\
\text { sewage }(\%)\end{array}$ & $85 \sim 100$ & $75 \sim 85$ & $65 \sim 75$ & $55 \sim 65$ & $45 \sim 55$ \\
\hline & \multirow{2}{*}{$\begin{array}{l}\text { Environmental } \\
\text { quality }\end{array}$} & Surface water quality index (\%) & $90 \sim 100$ & $80 \sim 90$ & $70 \sim 80$ & $60 \sim 70$ & $50 \sim 60$ \\
\hline & & Air quality index (\%) & $90 \sim 100$ & $80 \sim 90$ & $70 \sim 80$ & $60 \sim 70$ & $50 \sim 60$ \\
\hline
\end{tabular}

according to the ecological environment condition standard and evaluation index of the ecological reserve, we construct the same characteristic matter element $R_{0}$ in the classic field:

$$
R_{0}=\left[\begin{array}{ccccc}
N & N_{1} & N_{2} & \cdots & N_{m} \\
C & V_{1} & V_{2} & \cdots & V_{m}
\end{array}\right]=\left[\begin{array}{ccccc}
N & N_{1} & N_{2} & \cdots & N_{m} \\
C_{1} & \left\langle a_{11}, b_{11}\right\rangle & \left\langle a_{12}, b_{12}\right\rangle & \cdots & \left\langle a_{1 m}, b_{1 m}\right\rangle \\
C_{2} & \left\langle a_{21}, b_{21}\right\rangle & \left\langle a_{22}, b_{22}\right\rangle & \cdots & \left\langle a_{2 m}, b_{2 m}\right\rangle \\
\vdots & \vdots & \vdots & \vdots & \vdots \\
C_{n} & \left\langle a_{n 1}, b_{n 1}\right\rangle & \left\langle a_{n 2}, b_{n 2}\right\rangle & \cdots & \left\langle a_{n m}, b_{n m}\right\rangle
\end{array}\right],
$$

where $N_{1}, N_{2}, \ldots, N_{m}$ are the classification levels of the same characteristic matter elements in the classical field, that is, the classification level of the evaluation index, $C_{i}$ is the $i$ th evaluation index, and $\left\langle a_{i j}, b_{i j}\right\rangle$ is the value range of the $j$ th category of the $i$ th evaluation index.

(2) Determine the segment field matter element $R_{p}$. According to the same characteristic matter element $R_{0}$ of the classic field and various segment fields, the segment field matter element can be determined:

$$
R_{p}=\left(P, C, X_{p}\right)=\left[\begin{array}{ccc}
P & C_{1} & V_{1 p} \\
& C_{2} & V_{2 p} \\
\vdots & \vdots \\
& C_{n} & V_{n p}
\end{array}\right]=\left[\begin{array}{ccc}
P & C_{1} & \left\langle a_{1 p}, b_{1 p}\right\rangle \\
& C_{2} & \left\langle a_{2 p}, b_{2 p}\right\rangle \\
\vdots & \vdots \\
& C_{n} & \left\langle a_{n p}, b_{n p}\right\rangle
\end{array}\right],
$$

where $P$ represents the entire category and $V_{i p}=$ $\left\langle a_{i p}, b_{i p}\right\rangle$ is the value range of the $i$ th evaluation index of $P$, that is, the section domain of $P$.

(3) Determine the first-level index $e$ as the matter element to be evaluated $R_{e}$. The determination of the matter element to be evaluated $R_{e}$ is based on the first-level indicators to be evaluated and the specific data of the second-level indicators contained in the first-level indicators. The matrix is

$$
R_{e}=\left(P_{e}, C, x_{i e}\right)=\left[\begin{array}{ccc}
P_{e} & C_{1} & x_{1 e} \\
& C_{2} & x_{2 e} \\
\vdots & \vdots \\
& C_{n} & x_{n e}
\end{array}\right]
$$

where $X_{i e}$ is the specific value of the $i$ th evaluation index of the evaluation object $e$. 
(4) Determine the correlation function of the secondlevel index. For the $i$ th second-level index in the firstlevel index, which belongs to the correlation function of different levels, the calculation formula is

$$
\begin{aligned}
k_{j}\left(x_{i e}\right)=\left\{\begin{array}{l}
\frac{\rho\left(x_{i e}, V_{i j}\right)}{\rho\left(x_{i e}, V_{i p}\right)-\rho\left(x_{i e}, V_{i j}\right)}, \\
\frac{\rho\left(x_{i e}, V_{i j}\right)}{\left(b_{i p}-a_{i p}\right)},
\end{array}\right. \\
\rho\left(x_{i e}, V_{i p}\right)-\rho\left(x_{i e}, V_{i j}\right) \neq 0, \\
\rho\left(x_{i e}, V_{i p}\right)-\rho\left(x_{i e}, V_{i j}\right)=0,
\end{aligned}
$$

$$
k(e)=k_{j}(e)=\left[a_{1}, a_{2}, \ldots, a_{n}\right] \cdot\left[\begin{array}{cccc}
k_{1}\left(x_{1 e}\right) & k_{2}\left(x_{1 e}\right) & \cdots & k_{m}\left(x_{1 e}\right) \\
k_{1}\left(x_{2 e}\right) & k_{2}\left(x_{2 e}\right) & \cdots & k_{m}\left(x_{2 e}\right) \\
\vdots & \vdots & \vdots & \vdots \\
k_{1}\left(x_{n e}\right) & k_{2}\left(x_{n e}\right) & \cdots & k_{m}\left(x_{n e}\right)
\end{array}\right] .
$$

where $X_{i e}$ is the specific value of the $i$ th evaluation index of the evaluation object $e$, where $\rho\left(x_{i e}, V_{i j}\right)$ and $\rho\left(x_{i e}, V_{i p}\right)$ are determined by the following formula:

$$
\left\{\begin{array}{l}
\rho\left(x_{i e}, V_{i j}\right)=\left|x_{i e}-\frac{\left(a_{i j}+b_{i j}\right)}{2}\right|-\frac{\left(b_{i j}-a_{i j}\right)}{2}, \\
\rho\left(x_{i e}, V_{i p}\right)=\left|x_{i e}-\frac{\left(a_{i p}+b_{i p}\right)}{2}\right|-\frac{\left(b_{i p}-a_{i p}\right)}{2} .
\end{array}\right.
$$

(5) Determine the comprehensive relevance of the firstlevel index $e$. Multiplying the second-level index weight vector $A=\left[a_{1}, a_{2}, \ldots, a_{n}\right]$ with the correlation matrix of each level of the second-level index, the correlation matrix of the first-level index can be calculated:
(6) Determine the evaluation level of the first-level index $e$. If $k_{j^{0}}(e)=\max _{j \in\{1,2, \ldots, m\}} k_{j}(e)$, it is determined that the first-level index $e$ belongs to the $j^{0}$ level:

$$
\begin{aligned}
\text { Let } \bar{k}_{j}(e) & =\frac{k_{j}(e)-\min _{j} k_{j}(e)}{\max _{j} k_{j}(e)-\min _{j} k_{j}(e)}, \\
j^{*} & =\frac{\sum_{j=1}^{m} j \bar{k}_{j}(e)}{\sum_{j=1}^{m} \bar{k}_{j}(e)},
\end{aligned}
$$

where $j^{*}$ is the characteristic value of the $e$-level of the first-level index to be evaluated, which is used to judge the degree to which the object to be evaluated is biased toward the adjacent level.

\subsubsection{Extension Evaluation Method of Evaluation Object.}

The extension evaluation method for the first-level indicators is introduced above. Assuming that the evaluation object has $q$ first-level indicators and the weight of each firstlevel indicator is $W=\left[w_{1}, w_{2}, \ldots, w_{q}\right]$, based on the evaluation results of the first-level indicators, the overall evaluation object can be evaluated. Multiplying the first-level index weight vector $A=\left[w_{1}, w_{2}, \ldots, w_{q}\right]$ with the first-level index eigenvalues, the eigenvalues of the overall evaluation object can be calculated:

$$
j^{\#}=\sum_{i=1}^{q} w_{i} j_{i}^{*} .
$$

\subsubsection{Determination of the Weights of Indicators at Different} Levels. The extension evaluation methods for different levels of indicators are introduced above, but the weight determination method is not introduced. The following describes how to determine the determination. The original weight is determined according to the relative value of the index of the evaluated object, resulting in changes in the weight. If the evaluation object is in different periods and the weight of the same index in different period changes, there will be contradictions in the evaluation results in different periods. Therefore, this paper selects entropy method to determine the index weight.

(1) Determination of the weights of second-level indicators. Assuming that a certain first-level level indicator contains $m$ second-level evaluation indicators, there are a total of $n$ years of data, and the original data matrix is formed as $X_{i j}=\left(x_{i j}\right)_{n \times m}$; the steps of using the entropy method to determine the indicator weight are as follows:

(i) Dimensionless processing of indicators: for a positive index, that is, the larger the index value, the better the index; the formula for the nondimensional processing of the index is

$$
x_{i j}^{\prime}=\frac{x_{i j}-\min x_{i j}}{\max x_{i j}-\min x_{i j}}, \quad(i=1,2, \ldots, n ; j=1,2, \ldots, m) .
$$

For the inverse index, that is, the smaller the index, the better the index; the formula for the nondimensional processing of the index is 


$$
x_{i j}^{\prime}=\frac{\max x_{i j}-x_{i j}}{\max x_{i j}-\min x_{i j}}, \quad(i=1,2, \ldots, n ; j=1,2, \ldots, m) .
$$

According to this, a normalized matrix is obtained: $X_{i j}^{\prime}=\left(x_{i j}^{\prime}\right)_{n \times m}$.

(ii) Calculate the proportion or probability $P_{i j}$ of the data after dimensionless processing. Calculate the proportion or probability of the $j$ th index and the $i$ th data after dimensionless processing. The formula is

$$
p_{i j}=\frac{x_{i j}^{\prime}}{\sum_{i=1}^{n} x_{i j}^{\prime \prime}}, \quad(i=1,2, \ldots, n ; j=1,2, \ldots, m) .
$$

(iii) Calculate the entropy value $e_{j}$ of the $j$ th index. The formula for calculating the entropy value of the $j$ th index is

$$
e_{j}=-\frac{1}{\ln n} \sum_{i=1}^{n} p_{i j} \ln p_{i j}, \quad(j=1,2, \ldots, m) .
$$

$\ln$ is the natural logarithm, $e_{j} \geq 0$.

(iv) Calculate the difference coefficient $c_{j}$ of the $j$ th index. Define the coefficient of difference as

$$
c_{j}=1-e_{j}
$$

The larger the $c_{j}$, the more important the index.

(v) Calculate the weight $a_{j}$ of the $j$ th index. The weight formula of the $j$ th index is

$$
a_{j}=\frac{c_{j}}{\sum_{j=1}^{m} c_{j}}, \quad(j=1,2, \ldots, m) .
$$

(2) Determination of the weight of the first-level evaluation index. The extension evaluation method of the first-level index has been introduced above. The eigenvalue $j^{*}$ of each first-level index of the evaluation matter element $e$ is calculated according to the degree of relevance, and the weight of each first-level index is carried out according to the eigenvalue $j^{*}$ of the first-level index. Assuming that the evaluation object is divided into $q$ first-level indicators with a total of $n$ years, the first-level indicator characteristic value $j^{*}$ data matrix is formed as $J_{i j}^{*}=\left(j_{i j}^{*}\right)_{n \times q}$, and the entropy method formulas (10) to (15) can be used to determine the weight of each first-level evaluation index $W=\left[w_{1}, w_{2}, \ldots, w_{q}\right]$.

\section{Application of Comprehensive Evaluation Model}

In December 2019, China's Hebei provincial government issued a document to determine the "Implementation Opinions on the construction planning of Zhangjiakou capital water conservation functional area and ecological environment support area (2019-2035)," and Zhangjiakou was listed as China's ecological reserve for construction. Therefore, this paper takes Zhangjiakou ecological reserve as an example to evaluate the regional ecological environment objectively and scientifically, so as to provide data support for comprehensively mastering the regional ecological environment quality.

5.1. Determination of the Weights of Second-Level Indicators. In order to evaluate the environmental quality of Zhangjiakou Ecological Conservation Zone, 13 index data of Zhangjiakou City from 2008 to 2019 were collected, and the weight of each second-level index was calculated according to formulas (10) to (15). See Table 2, for specific data.

5.2. First-Level Index Evaluation. Using the collected data of 13 indicators in the ecological reserve of Zhangjiakou City from 2008 to 2019 and the weight of each indicator in Table 2, the characteristic values of each first-level indicator are calculated according to formulas (4) to (9). In order to fully understand the environmental quality assessment results of Zhangjiakou Ecological Conservation Zone, all the characteristic values of the first-level indicators are listed in Table 3 . It can be seen from Table 4 that the environmental quality gaps in different aspects of the ecological reserves in this area are relatively large. The ecological function of this area is the worst, and it is in the Class V every year. In terms of ecological structure, it was Class II from 2008 to 2013 and became Class I after 2011. In terms of pollution load, it was Class IV from 2008 to 2012, and it has improved year by year from 2013, starting from Class III and then becoming Class I. In terms of environmental control, it was classified as Class V in 2008 and changed the most to Class I in 2013. In terms of environmental quality, it was Class II from 2008 to 2013 and Class I in subsequent years.

5.3. Determination of the First-Level Weight. Using the characteristic value $j^{*}$ of each primary indicator in Table 3, calculate the weight of each primary indicator according to formulas (10)-(15). See Table 4, for specific data.

5.4. Comprehensive Assessment of Environmental Quality. Using the weight of each primary indicator and the characteristic value $j^{*}$ of the primary indicator, calculate the characteristic value $j^{\#}$ of the evaluation object in different years according to formula (9). See the last column of Table 3 , for specific data. It can be seen from Table 3 that the characteristic value of the ecological environment in this area is getting smaller year by year. The characteristic value in 2008 was 3.529, and it became 1.99 in 2019, reflecting that the environmental quality of the ecological reserve in the region is improving year by year. 
TABLE 2: The weights of the second-level indicators of the environmental quality assessment of the ecological reserve in Zhangjiakou city.

\begin{tabular}{|c|c|c|c|c|}
\hline First-level indicators & Second-level indicators & Entropy $\left(e_{j}\right)$ & Coefficient of difference $\left(g_{j}\right)$ & $\begin{array}{l}\text { Index weight } \\
\left(a_{j}\right)\end{array}$ \\
\hline \multirow{2}{*}{ Ecological function } & Water resources per capita & 0.6978 & 0.3022 & 0.5070 \\
\hline & The population density & 0.7058 & 0.2942 & 0.4930 \\
\hline \multirow{2}{*}{ Ecological structure } & Forest cover rate & 0.9108 & 0.0892 & 0.5100 \\
\hline & Green coverage rate in built-up area & 0.9143 & 0.0857 & 0.4900 \\
\hline \multirow{4}{*}{ Pollution load } & Solid waste emission intensity & 0.8863 & 0.1137 & 0.3710 \\
\hline & Wastewater discharge intensity & 0.9405 & 0.0595 & 0.1950 \\
\hline & Industrial sulfur dioxide emission intensity & 0.9389 & 0.0611 & 0.1990 \\
\hline & Industrial smoke emission intensity & 0.9281 & 0.0719 & 0.2350 \\
\hline \multirow{3}{*}{$\begin{array}{l}\text { Environmental } \\
\text { control }\end{array}$} & $\begin{array}{l}\text { Comprehensive utilization rate of industrial solid } \\
\text { waste }\end{array}$ & 0.8821 & 0.1179 & 0.5080 \\
\hline & Waste innocuous treatment rate & 0.9398 & 0.0602 & 0.2600 \\
\hline & Centralized treatment rate of urban sewage & 0.9460 & 0.0540 & 0.2330 \\
\hline \multirow{2}{*}{ Environmental quality } & Surface water quality index & 0.9610 & 0.0390 & 0.2880 \\
\hline & Air quality index & 0.9037 & 0.0963 & 0.7120 \\
\hline
\end{tabular}

TABLE 3: The eigenvalues and comprehensive eigenvalues of the first-level indicators of environmental quality in Zhangjiakou Ecological Conservation Zone.

\begin{tabular}{|c|c|c|c|c|c|c|c|c|c|c|c|}
\hline \multirow[t]{2}{*}{ Year } & \multicolumn{2}{|c|}{$\begin{array}{l}\text { Ecological } \\
\text { function }\end{array}$} & \multicolumn{2}{|c|}{$\begin{array}{l}\text { Ecological } \\
\text { structure }\end{array}$} & \multicolumn{2}{|c|}{ Pollution load } & \multicolumn{2}{|c|}{$\begin{array}{l}\text { Environmental } \\
\text { control }\end{array}$} & \multicolumn{2}{|c|}{$\begin{array}{c}\text { Environmental } \\
\text { quality }\end{array}$} & \multirow{2}{*}{$\begin{array}{c}\text { Overall } \\
j^{\#}\end{array}$} \\
\hline & $j^{0}$ & $j^{*}$ & $j^{0}$ & $j^{*}$ & $j^{0}$ & $j^{*}$ & $j^{0}$ & $j^{*}$ & $j^{0}$ & $j^{*}$ & \\
\hline 2008 & 5 & 4.848 & 2 & 2.423 & 4 & 4.062 & 5 & 4.253 & 2 & 1.835 & 3.529 \\
\hline 2009 & 5 & 4.844 & 2 & 2.418 & 4 & 4.040 & 4 & 3.680 & 2 & 1.962 & 3.440 \\
\hline 2010 & 5 & 4.814 & 2 & 2.119 & 4 & 4.016 & 5 & 4.918 & 2 & 2.024 & 3.604 \\
\hline 2011 & 5 & 4.804 & 2 & 1.994 & 4 & 3.758 & 5 & 4.406 & 2 & 2.006 & 3.398 \\
\hline 2012 & 5 & 4.795 & 2 & 1.947 & 4 & 3.566 & 5 & 4.089 & 2 & 1.881 & 3.246 \\
\hline 2013 & 5 & 4.785 & 2 & 1.926 & 3 & 3.754 & 1 & 2.114 & 2 & 1.835 & 2.947 \\
\hline 2014 & 5 & 4.781 & 1 & 1.688 & 3 & 2.920 & 1 & 1.660 & 1 & 1.944 & 2.559 \\
\hline 2015 & 5 & 4.780 & 1 & 1.508 & 2 & 2.417 & 1 & 1.619 & 1 & 1.865 & 2.334 \\
\hline 2016 & 5 & 4.778 & 1 & 1.664 & 2 & 2.360 & 1 & 1.343 & 1 & 1.835 & 2.289 \\
\hline 2017 & 5 & 4.773 & 1 & 1.658 & 1 & 1.970 & 1 & 1.438 & 1 & 1.832 & 2.171 \\
\hline 2018 & 5 & 4.773 & 1 & 1.329 & 1 & 1.590 & 1 & 1.886 & 1 & 1.802 & 2.056 \\
\hline 2019 & 5 & 4.779 & 1 & 1.365 & 1 & 1.574 & 1 & 1.607 & 1 & 1.697 & 1.991 \\
\hline
\end{tabular}

TABLE 4: The weights of the first-level indicators of the environmental quality assessment of the ecological conservation zone in Zhangjiakou City.

\begin{tabular}{lccc}
\hline Second-level indicators & Entropy $\left(e_{j}\right)$ & Coefficient of difference $\left(g_{j}\right)$ & Index weight $\left(w_{j}\right)$ \\
\hline Ecological function & 0.9272 & 0.0728 & 0.1330 \\
Ecological structure & 0.9007 & 0.0993 & 0.1810 \\
Environmental load & 0.8135 & 0.1865 & 0.3339 \\
Environmental control & 0.9027 & 0.0973 & 0.1770 \\
Environmental quality & 0.9068 & 0.0932 & 0.1700 \\
\hline
\end{tabular}

\section{Conclusion}

According to the characteristics of the ecological reserve, the environmental quality evaluation index system and the extension evaluation model of the ecological reserve are constructed, and the environmental quality of the ecological reserve of Zhangjiakou City is dynamically evaluated using the model. The conclusions are as follows:

(1) The evaluation of the environmental quality of the regional ecological reserve through the constructed extension evaluation model can accurately, objectively, and comprehensively evaluate the environmental quality of the regional ecological conservation, and it can also evaluate different aspects of the environmental quality of the ecological reserve.

(2) The improvement of the entropy weight method to determine the weights of indicators at all levels not only effectively overcomes the shortcomings of subjective weight determination but also enables dynamic comparison and evaluation of the environmental quality of regional ecological reserves and understands the trend of regional environmental quality changes from a dynamic perspective. 
(3) Through the application of the construction model to evaluate the environmental quality of Zhangiiakou Ecological reserve, it is possible to grasp the status and change trend of different aspects of the environmental quality of the area. Based on the evaluation results, relevant policies can be formulated, and corresponding measures can be taken to continuously improve the quality of the ecological environment in the region.

\section{Data Availability}

In order to evaluate the environmental quality of Zhangjiakou Ecological Conservation Zone, 13 index data of Zhangjiakou City from 2008 to 2019 were collected, such as pollution load, ecological structure, and environmental quality. All the data used to support the findings of this study are included within the article.

\section{Conflicts of Interest}

The authors declare that they have no conflicts of interest.

\section{References}

[1] L. C. Dong and X. Z. Mu, "Research on comprehensive evaluation index system of beijing ecological conservation development zone," China Market, vol. 40, pp. 60-62, 2009.

[2] G. L. Xu, Z. H. Xu, and Q. Li, "Study on index system of ecological environmental assessment for the water conservation zone located in the south of Ji'nan city," Environmental Protection Science, vol. 31, no. 5, pp. 60-62, 2005.

[3] Y. S. Lin, "Eco-environmental assessment of water conservation national key ecological function areas-a case study of Fujian province LIN yunshan," Journal of Fuqing Branch of Fujian Normal University, vol. 2, pp. 94-100, 2018.

[4] Y.F. Gan and X. Zhang, "Analysis and evaluation of ecological status of the national key ecological function zones in the Changjiang river economic belt," Surveying and Mapping of Sichuan, vol. 42, no. 1, pp. 36-41, 2019.

[5] Q. Zhang and Z. C. Du, "Evaluation research on regional ecological security of silk road economic belt: a case study of Qilian mountains and water conservation ecological functional district province," Ecological Economy, vol. 32, no. 10, pp. 168-174, 2016.

[6] L. H. Chai and D. Lha, "A new approach of deriving indicators and comprehensive measure for ecological environmental quality assessment," Ecological Indicators, vol. 85, pp. 716728, 2018.

[7] S. M. Jia, Q. Zhang, and L. Lu, "Evaluation on eco-environment sensibility in ecological conservation area of Daqing river watershed of Beijing," Urban Geology, vol. 14, no. 3, pp. 3-6, 2019.

[8] Y. N. Chai, G. J. Wei, W. Hou, Z.-X. Feng, and L. Zhai, "Multiscale eco-environmental quality evaluation method from a spatial perspective," Chinese Journal of Ecology, vol. 37, no. 2, pp. 596-604, 2018.

[9] B. J. Gao and M. Y. Chen, "A review of eco-environmental quality assessment," Forestry and Ecological Sciences, vol. 33, no. 1, pp. 1-6, 2018.

[10] W. Y. Yu, S. J. Zhang, H. T. Shen, and R. D. Wang, "Surface water quality evaluation based on fuzzy matter element method," Statistics \& Decisions, vol. 1, pp. 72-74, 2019.
[11] Z. S. Liu, J. C. Shang, and K. Jin, "Analysis of coordinated development between resourceful county economy and ecoenvironment in eastern Jilin province," Journal of Jilin University (Earth Science Edition), vol. 36, no. 2, pp. 225-229, 2006.

[12] H. Y. Wang, "Research on the vulnerability's synthetic evaluation and application of the regional and social economy system," pp. 29-31, Yanshan University, Qinhuangdao, China, 2012, Doctoral Dissertation. 